\title{
Were last glacial climate events simultaneous between Greenland and France? A quantitative comparison using non-tuned chronologies
}

M. Blaauw ${ }^{1 *}$, B. Wohlfarth ${ }^{2}$, J. A. Christen ${ }^{3}$, L. Ampel ${ }^{4}$, D. Veres ${ }^{4,5}$, K. A. Hughen ${ }^{6}$, F. Preusser ${ }^{7}$, and A. Svensson ${ }^{8}$

1 School of Geography, Archaeology and Palaeoecology, Queen's University Belfast, UK

2 Department of Geology and Geochemistry, Stockholm University, Sweden

3 Centro de Investigación en Matemáticas CIMAT, Guanajuato, Mexico

4 Department of Physical Geography and Quaternary Geology, Stockholm University, Sweden

5 "Emil Racovita" Institute of Speleology, Cluj-Napoca, Romania

6 Woods Hole Oceanographic Institution, MA, USA

7 Institut für Geologie, Universität Bern, Switzerland

8 Ice and Climate Research, Niels Bohr Institute, University of Copenhagen, Copenhagen, Denmark

* Corresponding author (maarten.blaauw@qub.ac.uk)

\begin{abstract}
Several large abrupt climate fluctuations during the last glacial have been recorded in Greenland ice cores and archives from other regions. Often these Dansgaard-Oeschger events are assumed to have been synchronous over wide areas, and then used as tie-points to link chronologies between the proxy archives. However, it has not yet been tested independently whether or not these events were indeed synchronous over large areas. Here, we compare Dansgaard-Oeschger-type events in a well-dated record from south-eastern France with those in Greenland ice cores. Instead of assuming simultaneous climate events between both archives, we keep their age models independent. Even these well-dated archives possess large chronological uncertainties, that prevent us from inferring synchronous climate events at decadal to multi-centennial time scales. If possible, comparisons between proxy archives should be based on independent, non-tuned time-scales.
\end{abstract}

\section{Introduction}

Some of the most intriguing climatic features of the last glacial period are the large abrupt temperature fluctuations that recurred at millennial time-scales. These Dansgaard-Oeschger (D-O) events, originally seen in $\delta^{18} \mathrm{O}$ variations in Greenland ice cores (Dansgaard et al., 1993), have subsequently been reported from proxy archives around the North Atlantic (Bond et al., 1997; Allen et al., 1999; Cacho et al., 1999; Shackleton et al., 2000; Sánchez-Goñi et al., 2002; Voelker et al., 2002; Tzedakis et al., 2004; Roucoux et al., 2005; Andersen et al., 2006; Vautravers and Shackleton, 2006; Wohlfarth et al., 2008) and beyond (Wang et al.,2001; Hendy et al., 2002; Voelker et al., 2002; Burns et al., 2003; Rohling et al., 2003; Hughen et al., 2004; Turney et al., 2004). D-O events have been hypothesized to result from major shifts in North Atlantic meridional overturning circulation (Knutti et al., 2004; EPICA Community Members, 2006). A rapid atmospheric transmission of the signal could have led to more or less synchronous D-O style events within the Northern Hemisphere. Indeed, abrupt climatic events recognized in marine and terrestrial proxy time series are frequently reported to have been synchronous with Greenland D-O events (Bond et al., 1997; Allen et al., 1999; Cacho et al., 1999; Wang et al., 2001; 
Sánchez-Goñi et al., 2002; Burns et al., 2003; Hughen et al., 2004; Roucoux et al., 2005; Vautravers and Shackleton, 2006).

However, the inference of synchroneity between regions is constrained by numerous factors, including the response of the analysed marine or terrestrial proxies to local, regional and global climate signals, the temporal resolution of the studied sequence, and the applied age models. The lack of an internationally accepted radiocarbon $\left({ }^{14} \mathrm{C}\right)$ calibration curve beyond 26 thousand calibrated years before present (Reimer et al., 2004; van der Plicht et al., 2004) (cal ka BP), uncertain and time-dependent radiocarbon "reservoir age" offsets for glacial marine records (Muscheler et al., 2008) and chronological uncertainties of up to 2600 years (at 2 standard deviations) in the Greenland ice cores (Andersen et al., 2006) further add to this complexity. In order to overcome these difficulties, time scales and events in marine and terrestrial records are often tuned (artificially synchronized) to ice core chronologies (e.g., Bond et al., 1997; Cacho et al., 1999; Walker et al., 1999; Tzedakis et al., 2004; Skinner, 2008).

Tuning assumes synchronicity of major climatic/environmental events between multiple proxy archives. According to the tuning line of reasoning, major climatic events were so large that they must have been expressed in a wide spatial range of fossil proxy records. These synchronous proxy changes are then used as tie-points (points of equal age) between the archives, thus providing age-depth estimates for one core based on the age-model of a better dated "mother" time series (e.g., orbital forcing, Greenland ice cores, Hulu cave speleothems or stacked marine $\delta^{18} \mathrm{O}$ curves; Bond et al., 1997; Cacho et al., 1999; Tzedakis et al., 2004; Lisiecki and Raymo, 2005; Hughen et al., 2006). A good example of a tie-point is the North Atlantic Ash Zone II tephra, resulting from a single volcanic eruption, and deposited over a wide area as it has been encountered and identified geochemically in Greenland ice as well as in a range of North Atlantic marine sediment cores (Austin et al., 2004). This tephra, dated at c. 55,330 \pm 1184 cal BP in NGRIP (Svensson et al., 2008), was deposited during a major environmental event found both in marine and ice cores, and thus this event can safely be assumed to have been synchronous (interstadial 15, Bond et al., 1997; Austin et al., 2004). Even so, this tephra might have been produced by two volcanic eruptions separated by up to 2000 yr (Wåstegard et al., 2006).

Many other environmental events used to align glacial proxy archives are not accompanied by uniquely identifiable "finger prints". Instead, tie-points are often inferred based on the order, amplitudes and shapes (e.g., "tooth-like" or "w-shaped") of proxy curves, which in turn reflect the size and abruptness of climate change events (Bond et al., 1997; Shackleton et al., 2000; Tzedakis et al., 2004). Besides the tephra tie-point discussed above, only few event-based glacial tie-points have been dated independently (e.g., using radiocarbon dates); dating densities were often low and discrepancies between tuning and independent dates were at millennial scales (Hendy et al., 2002; Rohling et al., 2003; Shackleton et al., 2004; Svensson et al., 2006; Skinner, 2008). The "mother" chronologies themselves also possess considerable chronological uncertainties (e.g., 5000 yr for SPECMAP; Martinson et al., 1987), so any tuned "daughter" chronology will necessarily obtain larger errors (a combination of the uncertainties of the mother chronology, of the tuning process, and of the uncertain sedimentation histories between tiepoints). The assumption of synchronicity between regions eliminates any potential for objective evaluation of relative timing in different time scales (Walker et al., 1999; Wunsch, 2006; Blaauw et al., 2007a). Moreover, these climate-driven linkages are based on plausible yet unproven assumptions on regional to hemispheric connectivity (Wunsch, 2006), especially when many "stepping stones" are involved (e.g., from Greenland ice via the North Atlantic Ocean to the European mainland). 
Here, we test a different approach to compare D-O signals in Greenland ice cores (Andersen et al., 2006) with abrupt events recorded in the high resolution dated sediment sequence from the site Les Échets in south-eastern France (Wohlfarth et al., 2008). This multi-proxy lake record is dated with numerous radiocarbon and infra-red stimulated luminescence (IRSL) measurements, and covers the time period ca. 45-15 ka BP. The record displays pronounced environmental changes which show striking similarities to D-O events in the Greenland ice cores. Instead of imposing synchroneity through tuning of the proxy events, we apply Bayesian techniques (Blaauw et al., 2007a) to systematically compare the timing of the events recognized in the Les Échets sequence with those in the NGRIP ice core.

\section{Methods}

Core EC1 was drilled in the deepest part of the former lake at Les Échets (LE, 45 ${ }^{\circ} 54^{\prime}$ N, $4^{\circ} 56^{\prime}$ E, 275 m above sea level) and analysed at high temporal resolution for multiple environmental proxies (Wohlfarth et al., 2008). The alternating organic and inorganic sediments between 30.06 and $5 \mathrm{~m}$ depth were dated using 46 accelerator mass spectrometry (AMS) radiocarbon dates on plant remains, pollen grains, and the insoluble sediment organic fraction, as well as 21 IRSL dates (Wohlfarth et al., 2008). The major source of uncertainty for the ${ }^{14} \mathrm{C}$ dates lies in the calibration to calendar ages, whereas for the IRSL dates uncertainty resides in the variability of the water content of the sediments. Differential compaction of the organic and inorganic sediments indicates that their water content changed during and after deposition. Therefore present day moisture measurements were corrected using an estimated average water content of $80 \pm 10 \%$ over time.

Most of the LE radiocarbon ages are older than the limit of the IntCal04 calibration curve at 26 cal ka BP (Reimer et al., 2004). Although several curves for estimating calendar ages beyond that range are potentially available (Kitagawa and van der Plicht, 1998; Beck et al., 2001; van der Plicht et al., 2004; Fairbanks et al., 2005; Hughen et al., 2006; Danzeglocke et al., 2008), we chose here the curves of Hughen et al. (2006, hereafter called Hughen06), and Fairbanks et al. (2005, hereafter called Fairbanks05), because of their long time-spans, high-dating resolution and reasonable between-curve agreements. Both Kitagawa and van der Plicht (1998) and Beck et al. (2001) provide alternative glacial curves with a reasonably high density, but both curves are in disagreement with each other and with Hughen06 and Fairbanks05 during at least parts of our period of interest. While the calendar ages of Hughen06 are based on tuning Cariaco Basin sediment palaeoclimate records to the high-resolution U/ Th dated Hulu cave $\delta^{18} \mathrm{O}$ record (Wang et al., 2001), those of Fairbanks05 were constructed from nontuned, independently obtained U/Th dates on corals. Both curves have uncertainties in their calendar age models (errors 300-500 yr for Hughen06, 50-100 yr for Fairbanks05), and imprecisely known and possibly varying local marine reservoir effects (Muscheler et al., 2008) create additional uncertainties in the radiocarbon ages of both curves. In order to take into account the uncertainties on the calendar as well as the radiocarbon age scales, we re-sampled each data point of the Hughen06 or Fairbanks05 curve assuming normally distributed errors of the radiocarbon and calendar age estimates, and repeated this process 10,000 times. For each iteration we interpolated linearly between the sampled ${ }^{14} \mathrm{C}$ and cal $\mathrm{BP}$ points, to produce ${ }^{14} \mathrm{C}$ age point estimates at 50 calendar year intervals between 60 and $15 \mathrm{kcal} \mathrm{BP}$. For each of these calendar years, histograms of all ${ }^{14} \mathrm{C}$ age estimates were drawn to calculate $1 \mathrm{sd}$ highest posterior densities on the radiocarbon age scale. Calendar ages from the comparison curves 
produced above should not be considered to be as reliable as those derived from "official" IntCal calibration curves, and thus we refrain from using the term cal BP (van der Plicht et al, 2004).

The age models were constrained by prior information (for detailed explanations of the priors see Blaauw and Christen, 2005; Blaauw et al., 2007b): i) the depositional setting dictates that the dated depths must be ordered chronologically; $i$ ) given that $25 \mathrm{~m}$ of sediment had accumulated over c. $25 \mathrm{kyr}$, deposition rates of c. 5-20 yr/cm are considered most likely, and other (positive) accumulation rates are possible although less likely (Fig. 1a; AlphaM=12, AlphaStd=4); iii) the variable stratigraphy suggests that rapid accumulation rate changes and hiatuses could have occurred (Fig. 1b; Epsilon=2); iv) between sections hiatuses are most likely to be short or absent, but could at times last millennia (Fig. 1c; Hiatus $A=10^{-4}$, HiatusB $=10^{-5}$ ); and $v$ ) every date has a prior probability of being outlying ( $5 \%$ for most (57) dates; $50 \%$ for $7{ }^{14} \mathrm{C}$ dates which could not be pre-treated, had a sample weight $<1 \mathrm{mg}$ or were possibly altered by a hard-water effect). Because there were no stratigraphical or other indications for a hiatus at 1653 and $1605 \mathrm{~cm}$ (as opposed to around $2700 \mathrm{~cm}$; Wohlfarth et al., 2008), we assumed that the two dates at those depths were erroneous, and adapted their prior outlier probabilities to $95 \%$. The lowermost date (3097 cm depth) has not been pretreated and is therefore not considered to be reliable either. This part of the sediment sequence has several sand layers with sharp, erosive upper and lower boundaries, which indicate reworking and redeposition of sediments and likely also sedimentary hiatuses. This observation gives further evidence that the sediments in the lowest part of the analysed sequence might be older than suggested by the radiocarbon dates. Therefore we assigned $95 \%$ prior outlier probabilities (see below) to the lowermost two radiocarbon dates. Outlying dates were not removed but were identified and down-weighted automatically (see Blaauw and Christen, 2005). The IRSL and ${ }^{14} \mathrm{C}$ dates of LE were combined with the above prior information, producing $>1.7$ billion Markov Chain Monte Carlo age-depth models. Of these age-model iterations, through thinning 10,000 were retained for subsequent age-model analysis (Blaauw and Christen, 2005).

Most dates fit within 1 standard deviation (sd) of the comparison curves (radiocarbon) or the 1:1 curve (IRSL), with the exceptions of $i$ ) the lower part of the sequence where IRSL dates suggest much older ages than the radiocarbon dates, $i$ ) the upper part where IRSL dates suggest somewhat older ages than the radiocarbon dates, and iii) outlying radiocarbon dates between ca. 37-26 ka BP. The Bayesian agemodelling process automatically identifies and down-weights outlying dates; mean posterior outlier probabilities were c. $25 \%$ and $27 \%$ respectively for the Hughen06 and Fairbanks05 runs. During the age-modelling, all dates are used together while taking into account their stratigraphical ordering (Blaauw and Christen, 2005); as a result the age-model confidence intervals are generally much narrower than those of the individual dates. Histograms of the calendar age distribution can be obtained for every depth through calculating the assigned calendar age for each of the 10,000 iterations, and graphed as grey-scales where more likely calendar ages (appearing more frequently in the sampling process) are darker (Fig. 2c-d). The intervals with conflicting IRSL and radiocarbon dates obtained much larger chronological uncertainties (wide grey areas). We therefore focus on the high-resolution dated middle part of the sequence, between 40 and $26 \mathrm{ka} \mathrm{BP}$, where average 1 sd uncertainties are ca. 400 years.

The probability that an event took place in a proxy archive during a certain period depends on $i$ ) the archive's chronological uncertainty (Fig. 2), ii) the strength of the proxy evidence for an event (i.e. signal strength) (Fig. 3), and iii) the duration of the period or window width (indicated by colours in Fig. 4). Here we assess all of these uncertainty sources together by calculating the event probability 
within a time window for the individual archives. The LOI and planktonic diatom proxies of LE were normalized to $100 \%$ and re-sampled assuming normally distributed errors (1\% for LOI, $2 \%$ for diatoms), after which a running median was calculated (smoothing 25 for LOI, 11 for lower resolution diatom data). All depths $d$ where the running median increased beyond the error threshold were "flagged". This process was repeated 1000 times, after which for all depths of the individual proxies, the ratios of flagged iterations were plotted (Fig. 3a-b). The means of the ratios of both proxies estimate the probabilities of enhanced lake productivity (Fig. 3c). Depths with probabilities $<5 \%$ were neglected. For all age-model iterations of LE or NGRIP, we find those depths $d$, with event probabilities $p\left(e_{d}\right)$, that fall within a time-window with boundaries $y_{\max }$ and $y_{\min }$. The probability that an event took place in an archive during this time-window is equal to $1-\Pi\left(1-p\left(e_{d}\right)\right)$. In other words, we calculate the probability that no event took place within the time-window, which is the product of $1-p\left(e_{d}\right)$, and subtract this probability from 1 to find the probability that at least one event took place.

All calculations were performed in R (R Development Core Team, 2009; current version 2.9.0).

\section{Results}

Intervals of higher lake organic productivity (LE events A-G in Fig. 3), interpreted to reflect warmer and more humid climatic conditions, are indicated by rising values for loss-on-ignition (LOI) and planktonic diatom concentrations, synchronously with many other analysed proxies in LE sediments (Ampel et al., 2008; Wohlfarth et al., 2008; Veres et al., 2009). In contrast, low lake organic productivity, interpreted to reflect a colder and drier climate, is suggested by low values of LOI and planktonic diatom concentrations. Most of the LE warm events were accompanied by clear increases in arboreal pollen within the same core (Wohlfarth et al., 2008), suggesting that the environmental changes were regional at least. Peaks A-D clearly denote events of increased lake organic productivity (high event probabilities), whereas events E-G appear more subtle. Wohlfarth et al. (2008) suggested that the shifts between higher and low lake organic productivity phases resemble D-O and Greenland Interstadial (GI) events in the Greenland ice cores. Although it would be tempting to tune these intervals by eye to GI events 8-3 (Fig. 3), instead we calculate the statistical probability that both independently dated archives reacted simultaneously within certain time windows, taking into account their chronological uncertainties (Blaauw et al., 2007a).

Significant LE event probabilities (95\%) are only reached by employing time windows of 400 years or wider. The choice of ${ }^{14} \mathrm{C}$ comparison curve has a considerable effect on the timing of events A-D in particular, owing to disagreements between Hughen06 and Fairbanks05 around 37-34 ka BP. This disagreement is partly caused by Fairbanks05 having fewer evenly spaced data points for this time interval, and thus more kinks than Hughen06. Overlapping, closely spaced GI events (Fig. 4c) can hardly be distinguished from each other on an absolute time scale. Although the relative timing between GI events is well known (see below), NGRIP cumulative chronological uncertainties (Andersen et al., 2006) prevent us from assigning an individual GI event to any particular decade or even century ( $>95 \%$ event probabilities using time windows of $1550 \mathrm{yr}$ or wider).

To test for synchronous events between LE and NGRIP within a time-window, we can simply calculate the product of the event probabilities from the individual archives (Fig. 4d,e). High probabilities indicate that an event of increased lake organic productivity in Les Échets likely occurred simultaneously with a GI event, whereas low probabilities indicate the absence of a simultaneous 
reaction and/or a lack of information (e.g. hiatus, large chronological uncertainties). Probabilities of synchronous events between LE and NGRIP never reach $100 \%$ at centennial resolutions. For example, only within $>1000$ year time windows does it seem likely $(95 \%)$ that event LE-G co-occurred with one of the closely spaced GI events 4 or 3 in NGRIP. The other events show significant synchroneity using time windows of 1250 years or wider. In all cases, synchronous reactions at decadal to multi-centennial year resolution are very unlikely, since probabilities never exceed 10\% (red shades in Fig. 4d, e). Wider window sizes tend to reach higher event probabilities because $i$ ) the windows include more of the probability distributions of individual events, and ii) probability distributions of multiple separate events could cover the time windows considered.

Since the NGRIP time scale is based on annual layer counting, absolute chronological uncertainties accumulate to millennial scales over time during the glacial. However, cumulative layer-count errors between neighbouring GI events within NGRIP are much smaller, reaching centennial to decadal scales (Andersen et al., 2006). Therefore, the relative timings between GI events 8 to 3 are much more tightly constrained than those between the IRSL/ ${ }^{14} \mathrm{C}$ dated events LE-A to LE-G. Given the large absolute chronological uncertainties on the timing of individual events (Fig. 4), we investigate the patterns of timing between events (Fig. 5). Even if the absolute timings of events in either NGRIP or LE are erroneous, with a common climate mechanism forcing both the NGRIP and LE events, a shared "fingerprint" of the timing between events should be expected (but for similar event frequencies in unrelated climate series see Wunsch, 2006). Whereas the timing between LE events $F$ and $G$ is comparable to that between GI events 4 and 3, the relative timings between the other events differ by many centuries. Moreover, there appear to be more LE than GI events in the studied period.

We could postulate several reasons for the offsets between the timing of events between Les Échets and NGRIP, e.g. erroneous dates, large changes in marine reservoir age for the Hughen06 and Fairbanks05 curves, unrecognised hiatuses, low resolution, erosion and/or reworking of older layers in the LE record, missing or false proxy responses to climate change in either archive, or hundreds of "false" years in the NGRIP time scale (e.g., see Skinner, 2008). However, our approach shows that the assumption of synchronous events between both archives might be erroneous; the alternative explanation that the events were asynchronous should not be discarded.

\section{Discussion}

Our results appear to deviate from an apparently sound story based on a large body of stratigraphical studies (Bond et al., 1997; Cacho et al., 1999; Shackleton et al., 2000; Sánchez-Goñi et al., 2002; Rohling et al., 2003; Tzedakis et al., 2004; Roucoux et al., 2005; Skinner, 2008). It could be argued that our failure to find simultaneous events between Greenland and a terrestrial site in Europe was caused by proxy or dating problems (see above), and thus should not lead us to call into question the reported teleconnections between Greenland and other proxy archives. For example, within Mediterranean marine cores located relatively near to Les Échets, sea surface temperature and arboreal pollen content changed in concert (Sánchez-Goñi et al., 2002). Interestingly enough, the arboreal pollen records also show a close visual resemblance to that of Les Échets (Wohlfarth et al., 2008), indicating spatially wide-spread events of climate change. As the events in the Mediterranean cores were reportedly simultaneous with events in Greenland (Sánchez-Goñi et al., 2002), it should follow that Les Échets must have reacted simultaneously as well. However, the synchronicity of the Mediterranean climate events to those in 
Greenland is not surprising, since their chronologies were based on aligning foraminifera- $\delta^{18} \mathrm{O}$ resp. sea surface temperature fluctuations with $\delta^{18} \mathrm{O}$ peaks in the GISP2 ice core record.

Asynchronous climate events between proxy archives do not necessarily require us to invoke leads or lags, although these can be calculated and tested easily using our time-window method. Indeed, probably the safest (though most pessimistic) "zero-hypothesis" for any proxy-derived climate event would be to assume that it is unrelated to other events, until proven otherwise by independent, replicated data. However, millennial-scale chronological uncertainties for most of the last glacial period have prevented us from directly proving synchroneity of D-O events through independently dated archives. Over the years a plausible history of D-O events has been reconstructed, based on climatic reasoning combined with event-ages derived from tuning between archives. It should not be forgotten though that some degree of circular reasoning has necessarily been involved in this process. Indeed, it has been known for decades that assuming synchroneity of past climate/environmental events without independent confirmation (Walker et al., 1999) can lead to a 'reinforcement syndrome' (von Post, 1946; Smith and Pilcher, 1973; Baillie, 1991; Oldfield, 2001; Bennett, 2002).

Past climate research would benefit from a better quantification of the uncertainties involved. Until now, most tuning has been performed visually, involving subjective decisions. Statistical methods could be developed to better quantify the uncertainties of tuned age-models, e.g., based on (multi-proxy, multi-site) shape comparisons of events. In the longer run, one could envisage obtaining a better understanding of D-O events through a coupled ice/ocean/atmosphere/biosphere climate model guided by a spatial array of independently dated proxy events, while taking into account their chronological and other uncertainties. A step in this direction can be made by applying our time-window approach to a larger set of independently dated marine and/or terrestrial proxy archives.

The abrupt temperature fluctuations reconstructed from Greenland ice cores (Dansgaard et al., 1993; Steffensen et al., 2008) must have been forced by major climatic events, which arguably also should have had effects on larger spatial scales (Wunsch, 2006). However, most of the reported synchronous climate events outside Greenland were tuned to GI-events (Bond et al., 1997; Cacho et al., 1999; Shackleton et al., 2000; Sánchez-Goñi et al., 2002; Tzedakis et al., 2004; Roucoux et al., 2005; Skinner, 2008) and thus cannot themselves be used to infer synchroneity. Even with the highest resolution dated age-models (67 radiocarbon and IRSL dates for Les Échets, multi-proxy annual layer counting for Greenland; Andersen et al., 2006), chronological uncertainties are currently too high to resolve through independent chronologies whether last glacial D-O climate events were simultaneous, or even related, between Greenland and western Europe. These problems are even more serious with proxy archives dated and analysed at lower resolution. Although one would wish to resolve the spatio-temporal nature of past glacial climate events at annual or, at most, decadal scales, currently we are limited to comparisons at multi-centennial to millennial resolution only. However, this problem could be reduced significantly if more widespread time markers such as well-defined tephra layers were to be found.

\section{Acknowledgements}

BW acknowledges support from the Swedish Research Council (VR). MB thanks Keith Bennett for help at various stages of this paper. Comments from William D'Andrea, Maria Sánchez Goñi, John Lowe, Chronis Tzedakis and an anonymous referee on a previous version of this paper have helped 
improve it considerably. This is a contribution to ESF EuroCores on EuroCLIMATE project RESOLUTION.

\section{References}

Allen JRM, Brandt U, Brauer A, Hubberten H-W, Huntley B, Keller J, Kram M, Mackensen A, Mingram J, Negendank JFW, Nowaczyk NR, Oberhänsli H, Watts WA, Wulf S, Zolitschka B. 1999. Rapid environmental changes in southern Europe during the last glacial period. Nature 400: $740-743$. DOI: $10.1038 / 23432$

Ampel L, Wohlfarth B, Risberg J, Veres D. 2008. Paleolimnological response to millennial and centennial scale climate variability during MIS 3 and 2 as suggested by the diatom record in Les Échets, France. Quaternary Science Reviews 27: 1493-1504. DOI: 10.1016/j.quascirev.2008.04.014

Andersen KK, Svensson A, Johnsen SJ, Rasmussen SO, Bigler M, Röhlisberger R, Ruth U, SiggaardAndersen ML, Steffensen JP, Dahl-Jensen D, Vinther BM, Clausen HB. 2006. The Greenland ice core chronology 2005, 15-42 ka. Part 1: constructing the time scale. Quaternary Science Reviews 25: 32463257.

Austin WEN, Wilson LJ, Hunt JB. 2004. The age and chronostratigraphical significance of North Atlantic Ash Zone II. Journal of Quaternary Science 19: 137-146. DOI: 10.1002/jqs.821

Baillie MGL. 1991. Suck in and smear-two related chronological problems for the 90s. Journal of Theoretical Archaeology 2: 12-16.

Beck JW, Richards DA, Edwards RL, Silverman BW, Smart PL, Donahue DJ, Hererra-Osterheld S, Burr GS, Calsoyas L, Jull AJT, Biddulph D. 2001. Extremely large variations of atmospheric C-14 concentration during the last glacial period. Science 292: 2453-2458. DOI: 10.1126/science.1056649

Bennett KD. 2002. Comment: the Greenland 8200 cal. yr BP event detected in loss-on-ignition profiles in Norwegian lacustrine sediment sequences. Journal of Quaternary Science 17: 97-99. DOI: 10.1002/jqs.667

Blaauw M, Christen JA. 2005. Radiocarbon peat chronologies and environmental change. Applied Statistics 54: 805-816. DOI: 10.1111/j.1467-9876.2005.00516.x

Blaauw M, Christen JA, Mauquoy D, van der Plicht J, Bennett KD. 2007a. Testing the timing of radiocarbon-dated events between proxy archives. The Holocene 17: 283-288. DOI: $10.1177 / 0959683607075857$

Blaauw M, Bakker R, Christen JA, Hall VA, van der Plicht JA. 2007b. Bayesian framework for agemodelling of radiocarbon dated peat deposits: case studies from the Netherlands. Radiocarbon 49: 357367.

Bond G, Broecker W, Johnsen S, McManus J, Labeyrie L, Jouzel J, Bonani G. 1993. Correlations 
between climate records from North Atlantic sediments and Greenland ice. Nature 365: 143-147. DOI: $10.1038 / 365143 \mathrm{a} 0$

Burns SJ, Fleitmann D, Matter A, Al-Subbary AA. 2003. Indian Ocean climate and an absolute chronology over Dansgaard/Oeschger events 9 to 13 . Science 301: 1365-1367. DOI: $10.1126 /$ science. 1086227

Cacho I, Grimalt JO, Pelejero C, Canals M, Sierro FJ, Flores JA, Shackleton N. 1999. DansgaardOeschger and Heinrich event imprints in Alboran Sea paleotemperatures. Paleoceanography 14: 698705.

Dansgaard W, Johnsen SJ, Clausen HB, Dahl-Jensen D, Gundestrup NS, Hammer CU, Hvidberg CS, Steffensen JP, Sveinbjornsdottir AE, Jouzel J, Bond G. 1993. Evidence for general instability of past climate from a 250-kyr ice-core record. Nature 364: 218-220. DOI: 10.1038/364218a0

Danzeglocke U, Jöris O, Weninger B. CalPal-2007 ${ }^{\text {online }}$. http://www.calpal-online.de [23 March 2009]

EPICA Community Members. 2006. One-to-one coupling of glacial climate variability in Greenland and Antarctica. Nature 444: 195-198. DOI: 10.1038/nature05301

Fairbanks RG, Mortlock RA, Chiu TC, Cao T, Kaplan A, Guilderson TP, Fairbanks TW, Bloom AL, Grootes PM, Nadeau MJ. 2005. Radiocarbon calibration curve spanning 0 to 50,000 years BP based on paired 230Th/234U/238U and ${ }^{14} \mathrm{C}$ dates on pristine corals. Quaternary Science Reviews 24: 1781-1796. DOI: $10.1016 /$ j.quascirev.2005.04.007

Hendy IL, Kennett JP, Roark EB, Ingram BL. 2002. Apparent synchroneity of submillennial scale climate events between Greenland and Santa Barbara Basin, California from 30-10 ka. Quaternary Science Reviews 21: 1167-1184. DOI: 10.1016/S0277-3791(01)00138-X

Hughen K, Lehman S, Southon J, Overpeck J, Marshal O, Herring C, Turnbull J. 2004. ${ }^{14} \mathrm{C}$ activity and global carbon cycle changes over the past 50,000 years. Science 303: 202-207. DOI: 10.1126/science. 1090300

Hughen K, Southon J, Lehman S, Betrand C, Turnbull J. 2006. Marine-derived ${ }^{14} \mathrm{C}$ calibration and activity record for the past 50,000 years updated from the Cariaco Basin. Quaternary Science Reviews 25: 3216-3227. DOI: 10.1016/j.quascirev.2006.03.014

Kitagawa H, van der Plicht J. 1998. Atmospheric radiocarbon calibration to 45,000 yr B.P.: Late glacial fluctuations and cosmogenic isotope production. Science 279: 1187-1190. DOI: 10.1126/ science. 279.5354 .1187

Knutti R, Flückiger J, Stocker TF, Timmermann A. 2004. Strong hemispheric coupling of glacial climate through freshwater discharge and ocean circulation. Nature 430: 851-856. DOI: 10.1038/nature02786

Liesiecki LE, Raymo ME. 2005. A Pliocene-Pleistocene stack of 57 globally distributed benthic $\delta^{18} \mathrm{O}$ 
records. Paleoceanography 20: PA1003. DOI: 10.1029/2004PA001071

Martinson DG, Pisias NG, Hays JD, Imbrie J, Moore Jr. TC, Shackleton NJ. 1987. Age dating and the orbital theory of the ice ages: Development of a high-resolution 0 to 300,000-year chronostratigraphy. Quaternary Research 27: 1-29. DOI: 10.1016/0033-5894(87)90046-9

Muscheler R, Kromer B, Björck S, Svensson A, Friedrich M, Kaiser KF, Southon J. 2008. Tree rings and ice cores reveal ${ }^{14} \mathrm{C}$ calibration uncertainties during the Younger Dryas. Nature Geoscience 1: 263267.

Oldfield F. 2001. A question of timing: a comment on Hong, Jiang, Liu,. Zhou, Beer, Li, Leng, Hong and Qin. The Holocene 11: 123-124.

R Development Core Team, 2009. R: a language and environment for statistical computing. R Foundation for Statistical Computing, Vienna, Austria. ISBN 3-900051-07-0, URL http://www.Rproject.org.

Reimer PJ, Baillie MGL, Bard E, Bayliss A, Beck JW, Bertrand CJH, Blackwell PG, Buck CE, Burr GS, Cutler KB, Damon PE, Edwards RL, Fairbanks RG, Friedrich M, Guilderson TP, Hogg AG, Hughen KA, Kromer B, McCormac G, Manning S, Bronk Ramsey C, Remmele RWRS, Southon JR, Stuiver M, Talamo S, Taylor FW, van der Plicht J, Weyhenmeyer CE. 2004. INTCAL04 terrestrial radiocarbon age calibration, 0-26 cal kyr BP. Radiocarbon 46: 1029-1058.

Rohling EJ, Mayewski PA, Challenor P. 2003. On the timing and mechanism of millennial-scale climate variability during the last glacial cycle. Climate Dynamics 20: 257-267. DOI: 10.1007/s00382-0020266-4

Roucoux KH, de Abreu L, Shackleton NJ, Tzedakis PC. 2005. The response of NW Iberian vegetation to North Atlantic climate oscillations during the last 65 kyr. Quaternary Science Reviews 24: $1637-$ 1653. DOI: 10.1016/j.quascirev.2004.08.022

Sánchez-Goñi MF, Cacho I, Turon JL, Guiot J, Sierro FJ, Peypougoet JP, Grimalt JO, Shackleton NJ. 2002. Synchroneity between marine and terrestrial responses to millennial scale climatic variability during the last glacial period in the Mediterranean region, Climate Dynamics 19: 95-105. DOI: $10.1007 / \mathrm{s} 00382-001-0212-\mathrm{x}$

Shackleton NJ, Hall MA, Vincent E. 2000. Phase relationships between millennial-scale events 64,00024,000 years ago. Paleoceanography 15: 565-569.

Shackleton NJ, Fairbanks RG, Chiu T-C, Parrenin F. 2004. Absolute calibration of the Greenland time scale: implications for Antarctic time scales and for $\mathrm{D}^{14} \mathrm{C}$. Quaternary Science Reviews 23: 1513-1522. DOI: $10.1016 / j$.quascirev.2004.03.006

Skinner LC. 2008. Revisiting the absolute calibration of the Greenland ice-core age-scales. Climate of the Past 4: 295-302. 
Smith AG, Pilcher JR. 1973. Radiocarbon dates and vegetational history of the British Isles. New Phytologist 72: 903-914.

Steffensen JP, Andersen KK, Bigler M, Clausen HB, Dahl-Jensen D, Fischer H, Goto-Azuma K, Hansson M, Johnsen SJ, Jouzel J, Masson-Delmotte V, Popp T, Rasmussen SO, Röthlisberger R, Ruth U, Stauffer B, Siggaard-Andersen M-L, Sveinbjörnsdóttir ÁE, Svensson A, White JWC. 2008. HighResolution Greenland Ice Core Data Show Abrupt Climate Change Happens in Few Years. Science 321: 680-684. DOI: 10.1126/science.1157707

Svensson A, Andersen KK, Bigler M, Clausen HB, Dahl-Jensen D, Davies SM, Johnsen SJ, Muscheler R, Rasmussen SO, Röthlisberger R, Steffensen JP, Vinther BM. 2006. The Greenland Ice Core Chronology 2005, 15-42 ka. Part 2: comparison to other records. Quaternary Science Reviews 25: 3258-3267. DOI: 10.1016/j.quascirev.2006.08.003

Svensson A, Andersen KK, Bigler M, Clausen HB, Dahl-Jensen D, Davies SM, Johnsen SJ, Muscheler R, Parrenin F, Rasmussen SO, Röthlisberger R, Seierstad I, Steffensen JP, Vinther BM. 2008. A 60000 year Greenland stratigraphic ice core chronology. Climate of the Past 4: 47-57.

Turney CSM, Kershaw AP, Clemens SC, Branch N, Moss PT, Fifield LK. 2004. Millennial and orbital variations of El Niño/Southern Oscillation and high-latitude climate in the last glacial period. Nature 428: 306-310. DOI: $10.1038 /$ nature 02386

Tzedakis PC, Frogley MR, Lawson IT, Preece RC, Cacho RC, de Abreu L. 2004. Ecological thresholds and patterns of millennial-scale climate variability: The response of vegetation in Greece during the last glacial period. Geology 32: 109-112. DOI: 10.1130/G20118.1

van der Plicht J, Beck JW, Bard E, Baillie MGL, Blackwell PG, Buck CE, Friedrich M, Guilderson TP, Hughen KA, Kromer B, McCormac G, Ramsey CB, Reimer PJ, Reimer RW, Remmele S, Richards DA, Southon JR, Stuiver M, Weyhenmeyer CE. 2004. NotCal04 - comparison/calibration ${ }^{14} \mathrm{C}$ records $26-50$ cal kyr BP. Radiocarbon 46: 1225-1238.

Vautravers MJ, Shackleton NJ. 2006. Centennial-scale surface hydrology off Portugal during marine isotope stage 3: Insights from planktonic foraminiferal fauna variability. Paleoceanography 21: PA3004. DOI: 10.1029/2000PA000517

Veres D, Lallier-Vergès E, Wohlfarth B, Lacourse T, Kéravis D, Björck S, Preusser F, Andrieu-Ponel V, Ampel L. 2009. Climate-driven changes in lake conditions during late MIS 3 and MIS 2: a highresolution geochemical record from Les Échets, France. Boreas in press. DOI: 10.1111/j.15023885.2008.00066.x

Voelker AHL and workshop participants. 2002. Global distribution of centennial-scale records for Marine Isotope Stage (MIS) 3: a data base. Quaternary Science Reviews 21: 1185-1212. DOI: 10.1016/S0277-3791(01)00139-1

Von Post L. 1946. The prospect for pollen analysis in the study of the Earth's climatic history. New Phytologist 45: 198-203. 
Walker MJC, Björck S, Lowe JJ, Cwynar LC, Johnsen S, Knudsen K-L, Wohlfarth B, INTIMATE Group. 1999. Isotopic 'events' in the GRIP ice core: a stratotype for the late Pleistocene. Quaternary Science Reviews 18: 1143-1150. DOI: 10.1016/S0277-3791(99)00023-2

Wang Y, Cheng H, Edwards RL, An Z, Wu J, Shen CC, Dorale J A. 2001. A high-resolution absolutedated monsoon record from Hulu Cave, China. Science 294: 2345-2348. DOI: 10.1126/science.1064618

Wåstegard S, Rasmussen TL, Kuijpers A, Nielsen T, van Weering TCE. 2006. Composition and origin of ash zones from Marine Isotope Stages 3 and 2 in the North Atlantic. Quaternary Science Reviews 25: 2409-2419. DOI: 10.1016/j.quascirev.2006.03.001

Wohlfarth B, Veres D, Ampel L, Lacourse T, Blaauw M, Preusser F, Andrieu-Ponel V, Kéravis D, Lallier-Vergès E, Björck S, Davies SM, de Beaulieu J-L, Risberg J, Hormes A, Kasper HU, Possnert G, Reille M, Thouveny N, Zander A. 2008. Rapid ecosystem response to abrupt climate changes during the last glacial period in western Europe, 40-16 ka. Geology 36: 407-410. DOI: 10.1130/G24600A.1

Wunsch C. 2006. Abrupt climate change: An alternative view. Quaternary Research 65: 191-203. DOI: 10.1016/j.yqres.2005.10.006 


\section{Figure captions}

Fig. 1. Distributions of the prior information for the Les Échets age-depth model. All are gamma distributions, which are comparable to the Gaussian distribution, although values are always positive and distributions can be asymmetric. The prior for the accumulation rate within a section is shown in (a), with a mean of 12 and a variation of 4 (AlphaM=12, AlphaStd=4). Between sections, accumulation rate can vary according to a gamma distribution centred around 1 , with a variability set at epsilon=2 (b). Hiatus sizes (c) are most likely to be very short (0 yr or negligible), but stratigraphical information indicates hiatuses can occasionally last for several millennia (Hiatus $\mathrm{A}=10^{-4}$, HiatusB $=10^{-5}$ ).

Fig. 2. Bayesian age-depth models using two alternative radiocarbon comparison curves. The radiocarbon (black to red circles; redness indicates posterior outlier probability) dates of Les Échets were matched against the Hughen06 (green, a, c) and Fairbanks05 (red, b, d) comparison curves. Blue dashed curve is 1:1 line to which the IRSL dates (blue open diamonds) were matched. The age distributions are graphed as grey-scales (Blaauw et al., 2007a) (c-d). Dark areas indicate secure sections of the age-models, while lighter grey areas warn us of sections of a core where the chronological uncertainty is large.

Fig. 3. Les Échets proxies plotted against depth (black lines) and compared with the NGRIP $\delta{ }^{18} \mathrm{O}$ record (Dansgaard et al., 1993). Probabilities of enhanced lake productivity in Les Échets were calculated, through finding those depths with major increases in LOI (a) or planktonic diatoms (b) (see text). Clear increases of the individual proxies are plotted as yellow histograms. The means of these proxy increases estimate the probabilities of enhanced lake productivity (orange histograms in c). The events A-G of enhanced lake productivity could be tuned (grey connecting lines show possible links) to abrupt $\delta^{18} \mathrm{O}$ rises in NGRIP (Andersen et al., 2006), Greenland Isotope (GI) events 8 to 3 (d). Blue horizontal lines indicate $1 \mathrm{sd}$ dating confidence intervals of the GI events.

Fig. 4. Events of enhanced lake productivity in Les Échets from age-depth models using either Hughen06 (a) or Fairbanks05 (b), compared with GI-events in NGRIP (c). Probabilities of events of enhanced lake productivity (Les Échets) or temperature rises in Greenland (GI events from Andersen et al., 2006) were calculated using a time-window approach modified from Blaauw et al. (2007a) (see text). Time windows moved at 50 year jumps. Window sizes were 50 to 2000 years in steps of 50 years, shown as rainbow colours in the probability histograms (colour legend for window sizes is shown at bottom left). The histograms are centred at the mid-points of the time-windows, e.g., the probability of an event between 40 and $38 \mathrm{kyr} \mathrm{BP}$ is shown as the height of the violet colour at $39 \mathrm{kyr} \mathrm{BP}$. Histograms of narrower window sizes are plotted overlaying those of wider windows sizes (narrower histograms reach lower probabilities). The probabilities of simultaneous events between Les Échets and NGRIP within time windows are shown in $(\mathrm{d}, \mathrm{e})$.

Fig. 5. Timing in calendar years between neighbouring events of the Les Échets and NGRIP records. Colour shading shows the timing between Les Échets A to G using Hughen05 (green) or Fairbanks05 (red), and NGRIP GI events 8 to 3 (blue). Darker colours indicate more likely timing. Uncertainties of NGRIP timing are based on the accumulated counting error between neighbouring events (Andersen et al., 2006). There seem to be one more events in LE than in NGRIP during the period of study, which causes additional confusion when deciding which events to correlate. 

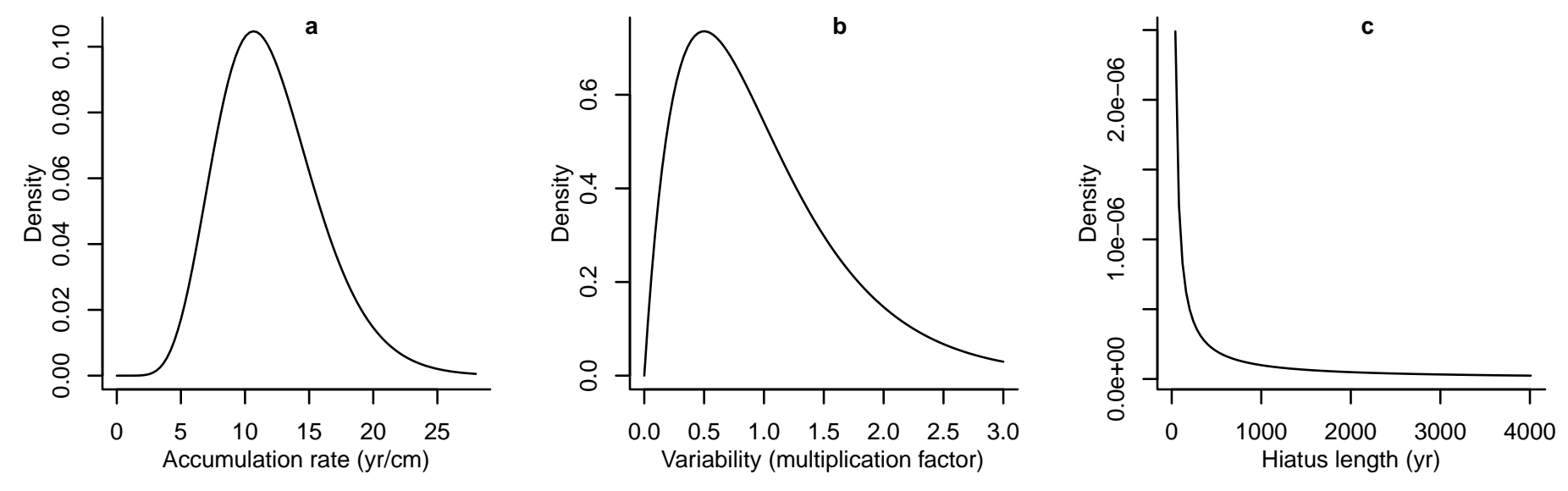

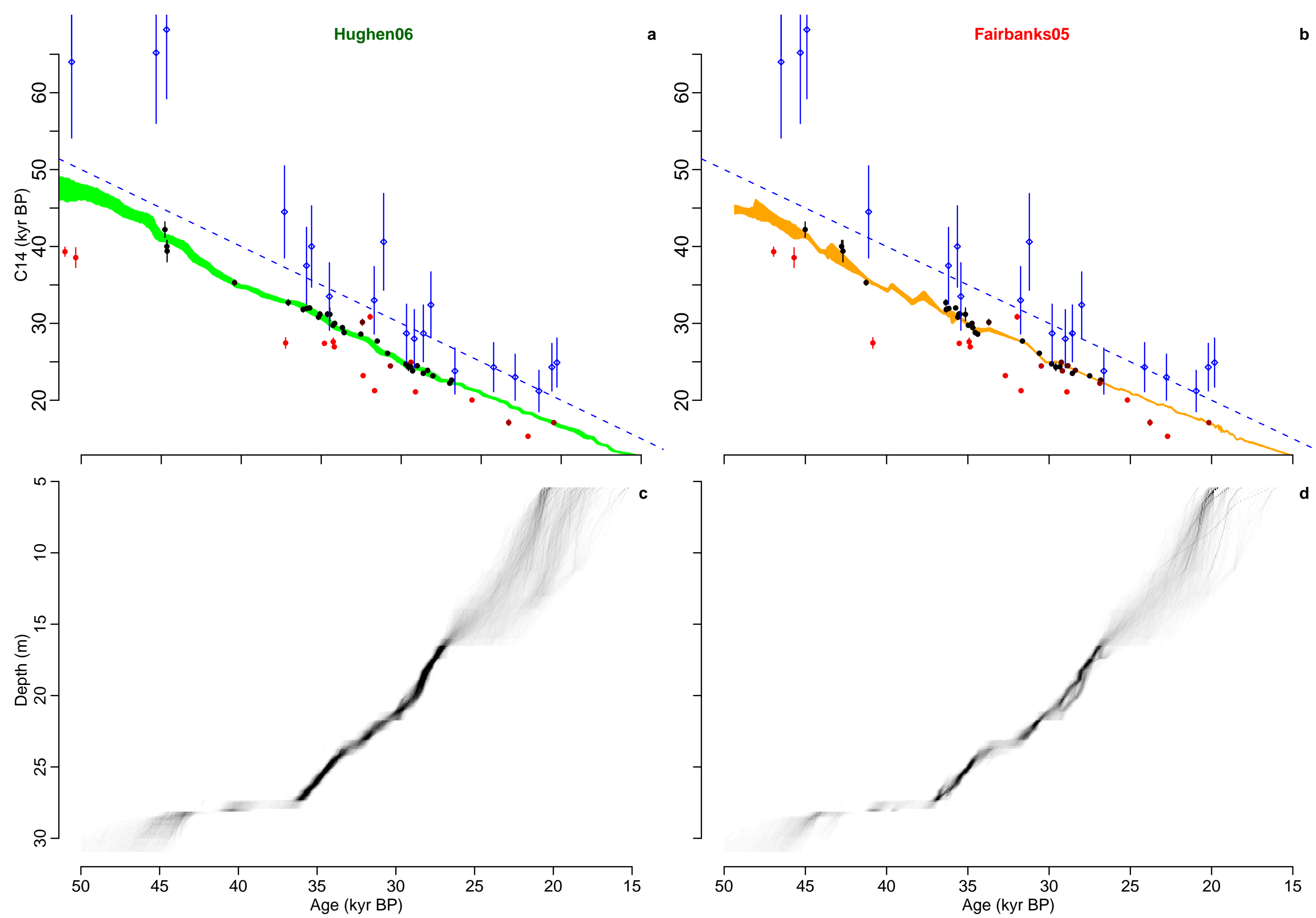


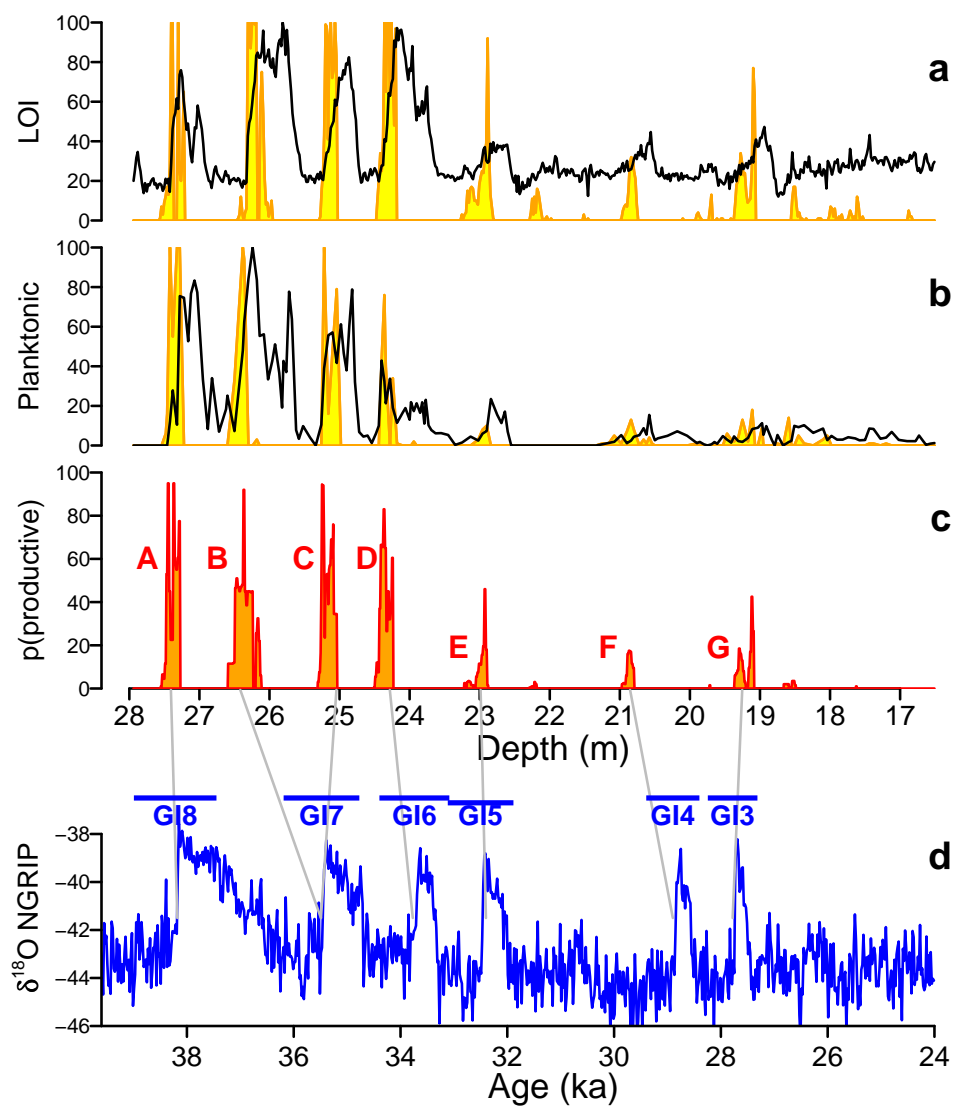


$F-G$

\section{4-3}

E-F

D-E

\section{6-5}

C-D

$$
\text { 7-6 }
$$

B-C

$$
\text { 8-7 }
$$

\begin{tabular}{|c|c|c|c|}
\hline \multicolumn{2}{|c|}{1} & \multicolumn{2}{|c|}{$T+1$} \\
\hline & 1000 & 2000 & 3000 \\
\hline
\end{tabular}

A-B

timing (yr) 